\title{
Prenatal Diagnosis and Management of Omphalocele: 2 Cases Report
} \author{
Rahaoui Mohamed $^{1 *}$, Zizi Hamza ${ }^{1}$, Mamouni Nisrine ${ }^{1}$, Errarhay Sanae ${ }^{1}$, Bouchikhi Chahrazed ${ }^{1}$, Banani Abdelaziz ${ }^{1}$,
} Bouabdallah Youssef $^{2}$

${ }^{1}$ Department of Gynecology and Obstetrics I, University Hospital Hassan II, Fez, Morocco

${ }^{2}$ Department of Pediatric Surgery, University Hospital Hassan II, Fez, Morocco

DOI: $10.36348 /$ sijog.2020.v03i03.007 $\quad$ | Received: 14.03 .2020 | Accepted: 21.03 .2020 | Published: 24.03 .2020

*Corresponding author: Dr. Rahaoui Mohamed

\section{Abstract}

Omphalocele (exomphalos) is one of the most common abdominal wall defects. The size of the defect and the severity of the associated anomalies determine the prognosis, the morbidity and mortality of this pathology. Prenatal screening and diagnosis of the abdominal wall defect and concurrent anomalies is important as it allows for effective prenatal counseling and optimal perinatal management. The purpose of this article is to discuss the approach to prenatal diagnosis and management of omphalocele through two cases reported.

Keywords: Omphalocele, Exomphalos, Prenatal diagnosis.

Copyright @ 2020: This is an open-access article distributed under the terms of the Creative Commons Attribution license which permits unrestricted use, distribution, and reproduction in any medium for non-commercial use (NonCommercial, or CC-BY-NC) provided the original author and source are credited.

\section{INTRODUCTION}

Omphalocele (exomphalos) is one of the most common congenital anterior abdominal wall defects which occur at the base of the umbilical cord, with herniation of the abdominal contents [1]. This midline defect which occurs at the umbilical ring often contains the midgut and other abdominal organs such as the liver, spleen and gonads [2]. The incidence of omphalocele is 1/3000 live births [3]. The etiology of omphalocele is not known. Various theories postulated include failure of the bowel to return into the abdomen by 12 weeks, failure of lateral mesodermal body folds to migrate centrally and persistence of the body stalk beyond 12 weeks of gestation. To date, three theories have been proposed concerning the etiology of omphalocele formation: the first is persistence of the primitive body stalk, the second is about the failure of the bowel to return to the abdomen, and the last incriminate the failure of complete lateral-body fold migration and body wall closure [4]. The hernia contents are encased in a three-layer covering: the outer amniotic layer, the middle Wharton's jelly layer and the inner peritoneal layer [2]. The size of an omphalocele varies between 2 and $10 \mathrm{~cm}$ and about $40-80 \%$ of all cases will have at least one concurrent anomaly (2): cardiac (7-47\%), gastrointestinal (3-20\%), genitourinary (6-20\%), chromosomal (3-20\%), musculoskeletal (4-25\%) and central nervous system $(4-30 \%)[2,5]$. The size of the defect and the severity of the associated anomalies impact the pre- and postnatal morbidity and [mortality $[6,7]$.

Omphaloceles are associated with other anomalies in more than $70 \%$ of cases, most of which are chromosomal 3], and can be detected during routine ultrasonographic examination.

Early screening allows prenatal counseling and safe delivery at a tertiary care center. We report here two cases of omphalocele detected at 16 and 25 weeks of gestation.

\section{Case $\mathbf{N}^{\circ} 1$}

A 23 year old primigravida, reported for routine antenatal ultrasound examination for the first time in the fourth month of pregnancy. There was no contributory family history of any congenital anomaly or spontaneous abortion. Ultrasound shows 16 weeks of gestation. The foetal abdominal scan revealed a $14 \mathrm{~mm}$ defect in the anterior abdominal wall in the midline with a mass in the midline protruding through the defect. The mass had a smooth surface covered by a thin membrane. The content of the mass had the same echotexture as that of the foetal liver, which herniated through the central abdominal defect. The umbilical 
cord was attached to the apex of the herniated mass (Figure-1). No foetal ascites or polyhydramnios was seen. No other anomaly was noted in the foetus. A diagnosis of omphalocele was made, and an amniocentesis was performed at 19 weeks of gestation and did not show any abnormalities (46 XX). The patient had a spontaneous abortion at 22 weeks of gestation. The post mortem examination shows a ruptured omphalocele (Figure-2).

\section{ILLUSTRATIONS}

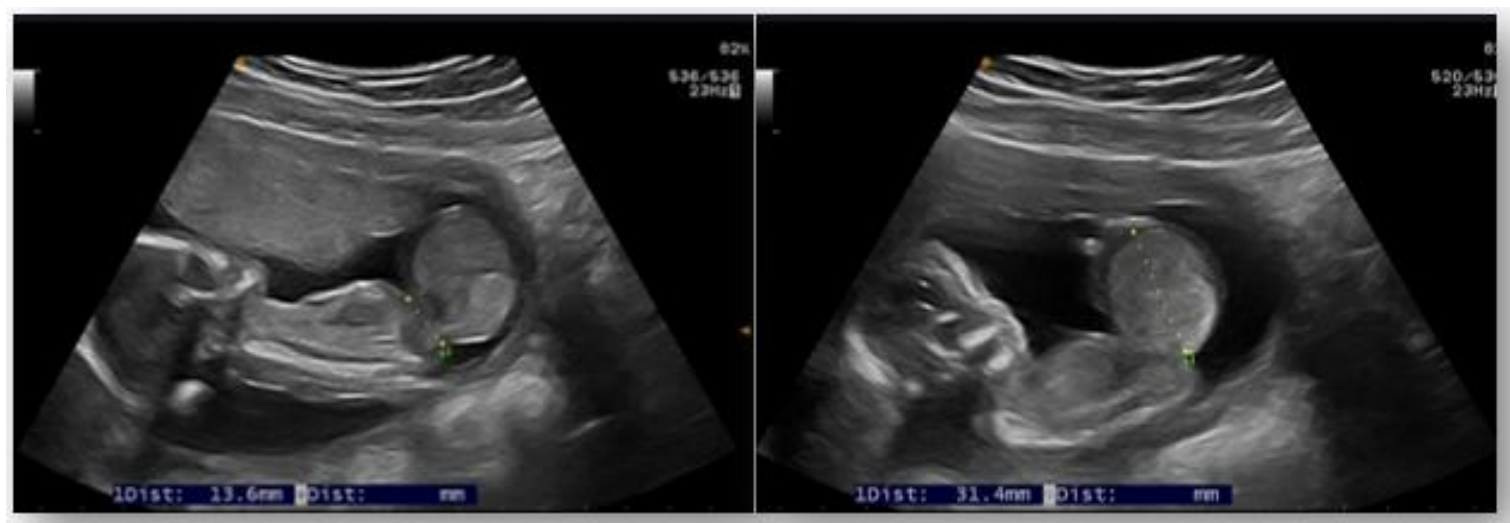

Fig-1: Prenatal US at 16 weeks showing an omphalocele containing the majority of the liver and a small portion of bowel

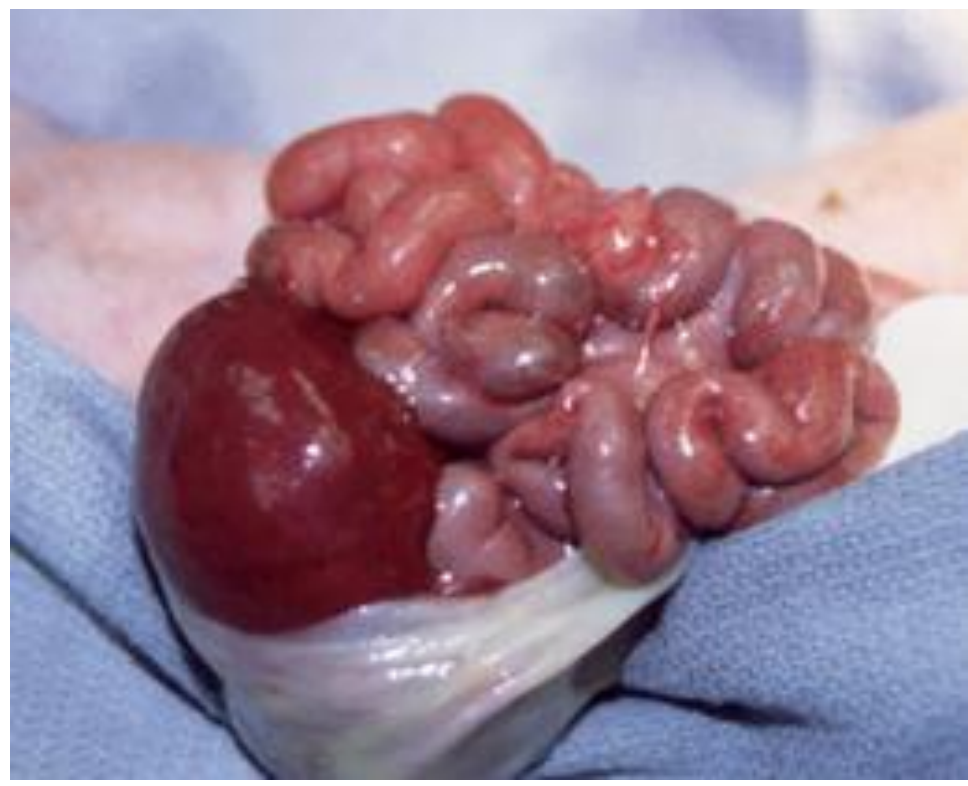

Fig-2: Postnatal appearance of ruptured omphalocele.

\section{Case $\mathbf{N}^{\circ} 2$}

This is a 32-year-old woman, G2P1, with no family history of malformation or genetics disorders. She was referred to our unit at 25 weeks, due to an omphalocele. The first scan performed at 11 weeks was normal. Ultrasound scan at 25 weeks revealed no polyhydramnios. There were no other associated anomalies. The omphalocele contained part of liver and bowels (Figure-3). The repeat scan performed at 28 and 32 weeks did not reveal any complications. Nevertheless at 32 weeks, a caesarean was performed due to maternal severe preeclampsia. The baby weight was $2300 \mathrm{~g}$. On the first day, the baby was hospitalized in neonatal unit. An external compression with traction of the omphalocele was done (Figure-4). The body wall traction was performed during two days. In the third day, a banding was repairing (Figure-5). The omphalocele was regressing. There were no hemodynamic or respiratory complications. At day four, an abdominal surgery was done in one step, without any complication. A $2 \mathrm{~cm}$ defect was still there. The omphalocele surgery was done with appendectomy. The postoperative follow up was strictly normal. 


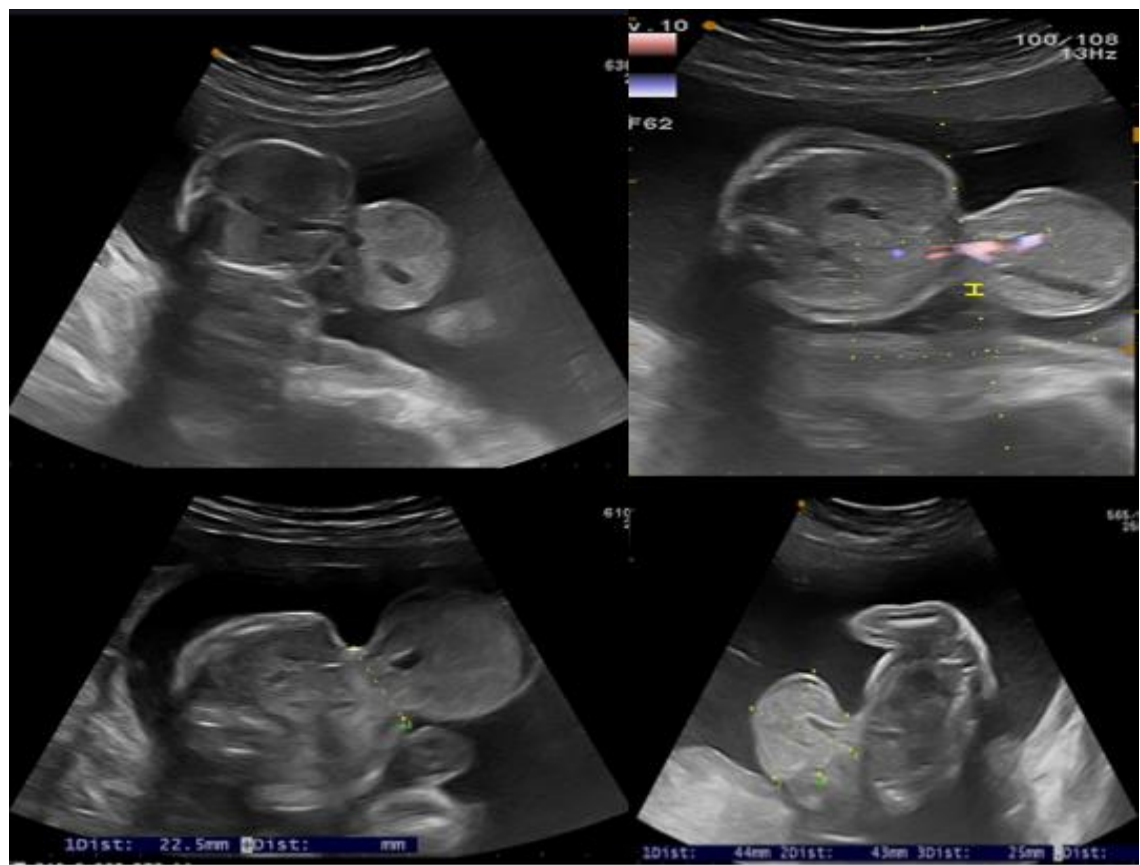

Fig-3: Prenatal US at 25 weeks showing an omphalocele containing the majority of the liver and a small portion of bowel

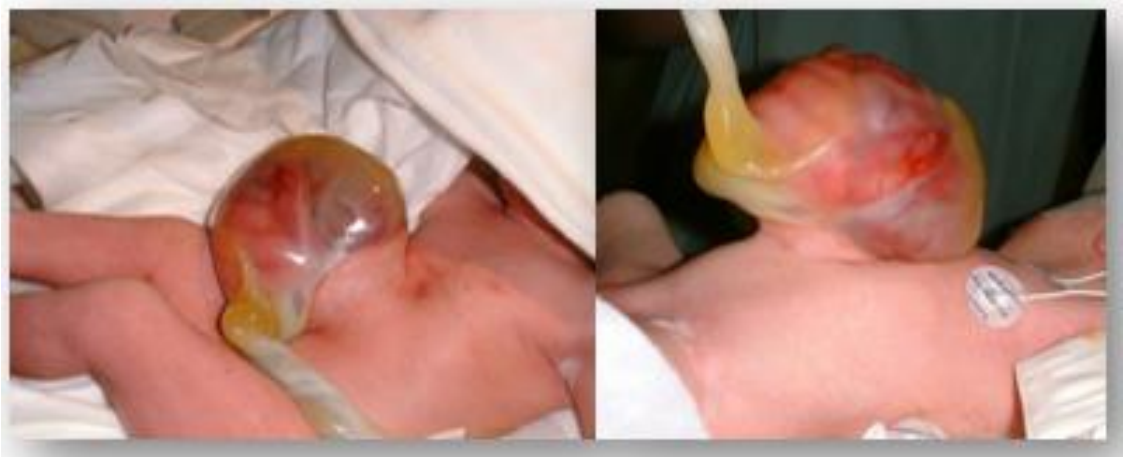

Fig-4: Postnatal view showing the landing omphalocele at day one

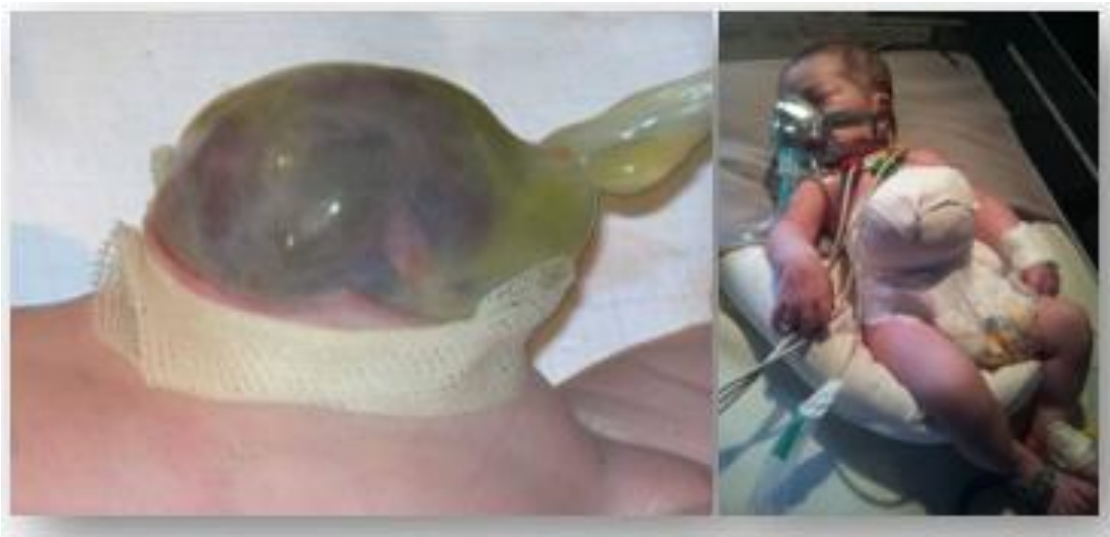

Fig-5: Postnatal view showing the compressing omphalocele at day three

\section{DISCUSSION}

Physiologic umbilical herniation occurs during the eighth week of embryonic development when the fetal midgut extends into the extraembryonic celom, occupying the proximal segment of the umbilical cord. The bowel undergoes a 270-degree counter clockwise rotation, the first 90 degree of which occurs by week 10 , extracoelomically at the base of the umbilicus. The remaining 180-degree clockwise turn occurs after the bowel returns to the abdomen. Rotation occurs around the axis of the superior mesenteric artery. The midgut returns to the abdominal cavity at 12 weeks of menstrual age. One of the theories regarding the causation of omphaloceles is failure of the bowel to return to the abdomen [5]. 
Associated anomalies are common (45-88\%) and their severity determines the prognosis. The chromosomal anomalies (40-60\%) include trisomies 18 , 13 and 21, Turner, Klinefelter and triploidy syndromes. The cardiac, genitourinary, gastrointestinal, musculoskeletal, neural tube and head neck defects with Beckwith-Wiedemann syndrome may also be present. It is thought that a chromosomal anomaly is more likely when oligohydramnios or polyhydramnios complicates the pregnancy. It has been reported that omphaloceles containing only bowel have a higher incidence of karyotypic abnormalities [6]. One recent study [8] has shown that periconceptional multivitamin use is associated with a $60 \%$ reduction in the risk of nonsyndromic omphalocele. The mortality rate is $80 \%$ when associated anomalies are present and it increases to $100 \%$ when chromosomal and cardiovascular anomalies are present. The size of the omphalocele does not affect prognosis. The male-to-female ratio is $1: 1$.

Ultrasonography is the imaging modality of choice for the prenatal assessment of the foetus. The earliest that an omphalocele can be detected is at 12 weeks of menstrual age. Magnetic resonance imaging (MRI) facilitates perinatal management and parental counseling [9]. An omphalocele is diagnosed on Ultrasonography when a fetal anterior midline mass consisting of abdominal contents that have herniated through a midline central defect at the base of umbilical insertion is demonstrated. The mean size of the defect is 2.5-5 cm, with fetal ascites. Polyhydramnios, and occasional oligohydramnios with associated anomalies are common [7]. A physiologic hernia seldom exceeds $7 \mathrm{~mm}$ in diameter or rarely persists after 12 weeks of gestation.

Other important differential diagnosis is gastroschisis, with herniation of the bowel through a small, off midline abdominal wall defect. This herniation protrudes into the amniotic cavity usually in the right paraumbilical region. Without covering membrane. Gastroschisis is the result from a vascular event of the omphalomesenteric artery [10]. Affected patients have malrotated bowel. Vascular compromise may occur from a volvulus, and it may result in bowel obstruction, ischemia or atresia. Besides malrotation, gastroschisis is not associated with other anomalies. Affected patient karyotypes are normal, and the prognosis is favourable.

\section{CONCLUSION}

The prenatal diagnosis of omphalocele remains significant. Additionally, early detection of other associated structural or chromosomal anomalies remains paramount as this has a direct correlation to the prenatal and postnatal prognosis. However, a significant number of omphalocele cases may still be diagnosed with an additional anomaly after birth. Therefore, particularly for large omphaloceles, timely prenatal counseling and management by a team of neonatologists, pediatric surgeons and obstetricians at a tertiary referral center with a neonatal intensive care unit and immediate access to surgical services will minimize the morbidity and mortality associated with this devastating congenital defect.

\section{REFERENCES}

1. Klein, M. D. (2012). Congenital defects of the abdominal wall. In: Coran, A. G., Adzick, N. S., eds. 7th ed. Pediatric Surgery, I, Philadelphia, PA: Elsevier Saunders; 973-984.

2. Cunningham, F. G., Norman, F. G., \& John, C. H. (2001). Ultrasound and Doppler. In: Cunningham, F. G. editor. Williams Obstetrics. 21st ed. United States of America: Mc Graw-Hill, 1126-1127.

3. Duke, S. M. Z. (2009). Omphalocele and gastroschisis. In: Puri, P. H. M., ed. Pediatric Surgery. Berlin, Heidelberg: Springer; 619-627.

4. Jo-Ann, M. J., \& David, A. N. (1998). Chromosomal Abnormalities. In: Carol, M. R., Stephanie, R. W., \& William, C. J., editors. Diagnostic Ultrasound. 2nd ed. St. Louis: Mosby, 1192-3.

5. Abrahamson, J. (1997). Hernias. In: Michael, J. Z., Seymour, I. S., \& Harold, E., ed. Maingot's Abdominal Operations. 10th ed. United States of America: Prentice Hall International Inc, 529-30.

6. Vasudevan, P. C., Cohen, M. C., Whitby, E. H., Anumba, D. O., \& Quarrell, O. W. (2006). The OEIS complex: two case reports that illustrate the spectrum of abnormalities and a review of the literature. Prenatal Diagnosis: Published in Affiliation With the International Society for Prenatal Diagnosis, 26(3), 267-272.

7. Anandakumar, C., Nuruddin Badruddin, M., Chua, T. M., Wong, Y. C., \& Chia, D. (2002). Firsttrimester prenatal diagnosis of omphalocele using three-dimensional ultrasonography. Ultrasound Obstet Gynecol, 20:635-636.

8. Botto, L. D., Mulinare, J., \& Erickson, J. D. (2002). Occurrence of omphalocele in relation to maternal multivitamin use: a population-based study. Pediatrics, 109(5), 904-908.

9. McMahon, C. J., Taylor, M. D., Cassady, C. I., Olutoye, O. O., \& Bezold, L. I. (2007). Diagnosis of pentalogy of Cantrell in the fetus using magnetic resonance imaging and ultrasound. Pediatric cardiology, 28(3), 172-175.

10. Wu, J. L., Fang, K. H., Yeh, G. P., Chou, P. H., \& Hsieh, C. T. C. (2004). Using color Doppler sonography to identify the perivesical umbilical arteries: a useful method in the prenatal diagnosis of omphalocele- exstrophy- imperforate anusspinal defects complex. Journal of ultrasound in medicine, 23(9), 1211-1215. 